\title{
REVIEW ARTICLE OPEN Microgravity metal processing: from undercooled liquids to bulk metallic glasses
}

\author{
Douglas C Hofmann ${ }^{1,2}$ and Scott N Roberts ${ }^{1,2}$
}

Bulk metallic glasses (BMGs) are a novel class of metal alloys that are poised for widespread commercialization. Over 30 years of NASA and ESA (as well as other space agency) funding for both ground-based and microgravity experiments has resulted in fundamental science data that have enabled commercial production. This review focuses on the history of microgravity BMG research, which includes experiments on the space shuttle, the ISS, ground-based experiments, commercial fabrication and currently funded efforts.

npj Microgravity (2015) 1, 15003; doi:10.1038/npjmgrav.2015.3; published online 27 May 2015

\section{INTRODUCTION}

One of the great successes of microgravity research has been in the development and commercialization of bulk metallic glasses (BMGs), a class of noncrystalline metal alloys that has stretched the scientific understanding of liquids, glasses and amorphous solids. ${ }^{1}$ Compared with conventional crystalline metal alloys, such as steel, aluminum, and titanium, BMGs are not well-defined materials, in that the mechanical properties of any one part are difficult to assess without destructive testing, even when similar processing conditions are used. For example, most mature crystalline metals can be fabricated utilizing well-prescribed procedures for alloying, processing, forming, and aging, which result in repeatable microstructures and mechanical properties. In contrast, BMGs are undercooled liquids that have been 'captured' as an amorphous solid by rapid cooling from above the liquidus temperature to below the glass transition temperature without intervening crystallization. This process is dynamic and largely uncontrolled, which results in a unique atomic arrangement in the final glass. Owing to the lack of crystals and grains, BMGs do not exhibit the same dislocation-based plasticity as crystalline metals, which imply that traditional metallurgy techniques for achieving uniform and repeatable mechanical properties cannot be used. Instead, the mechanical properties of BMGs are highly dependent on their processing history, and characterizing them above the liquidus temperature is paramount. As early as the 1980s, it was recognized that understanding the processing of glass-forming metal alloys would be critical to their development as an engineering material. For example, D Turnbull at Harvard argued that impurities in the liquid and contact with the container were responsible for crystallization in metallic glasses and that by fluxing alloys in a shell of boron-oxide, they could form bulk glasses with slower cooling rates. ${ }^{2,3}$ From these experiments it was clear that methods were needed to study glass-forming metal alloys, where melting could be decoupled from containers in an environment free of impurities. Fundamental thermophysical properties such as extent of undercooling, specific heat, thermal conductivity, emissivity, electrical conductivity, specific volume, density, viscosity, surface tension, and crystallization, among others, could then be obtained from the alloys.

For some glass-forming alloys, these data were achieved in a series of microgravity investigations onboard National Aeronautics and Space Administration's (NASA's) space shuttle during three missions during the 1990s (STS-65, STS-83, and STS-94). This study reviews some of the fundamental science on metallic glasses that was obtained using these microgravity experiments and how that data, in parallel with ground-based experimentation, laid the foundation for the larger BMG research field. It also discusses some early experiments demonstrating 'on-orbit' manufacturing of closed-cell BMG foams on the International Space Station (ISS), reviews current NASA-funded BMG programs for planned experiments on the ISS (not including many non-NASA-funded programs with similar aims), and reviews the history and current state of the art of the BMG commercial industry.

\section{DESCRIPTION OF BMGS AND METAL MATRIX COMPOSITES (BMGMCs)}

Compared with their crystalline counterparts, BMGs are complex materials to describe. In short, a BMG is a noncrystalline metal alloy that can be formed into a part thicker than $1 \mathrm{~mm}$ without crystallizing. The process of cooling a molten metal alloy without crystallization is called 'vitrification' and so BMGs are described as being 'vitrified metals', which has resulted in their most common trade name, 'Vitreloy'. BMGs are also metal alloys that exhibit an amorphous (or noncrystalline) atomic structure, which has led to them being termed 'amorphous metals.' The process of forming a BMG requires that a molten metal is undercooled below its glass transition temperature without crystallizing, which has also led the materials to be termed 'undercooled liquids,' although the description of undercooling can be broadly used to study the phenomenon in any metal alloy. BMGs also notably exhibit a glass transition temperature, where the alloys have an order of magnitude change in viscosity and a rapid increase in heat capacity. Therefore, BMGs are termed 'metallic glasses' for this reason.

\footnotetext{
${ }^{1}$ Materials Development and Manufacturing Technology Group, Jet Propulsion Laboratory/California Institute of Technology, Pasadena, CA, USA and ${ }^{2}$ Department of Materials Science and Applied Physics, Keck Laboratory of Engineering Sciences, California Institute of Technology, Pasadena, CA, USA.

Correspondence: DC Hofmann (dch@jpl.nasa.gov)

Received 31 October 2014; revised 22 January 2015; accepted 29 January 2015
} 
Regardless of their description, the mechanical properties and processing ability of BMGs make them a highly desirable class of metal alloys for many commercial applications. ${ }^{4}$ BMGs are typically designed around deep eutectics, which allow them to be cooled to below their glass transition temperature without nucleation and growth of crystals. BMGs therefore have low melting temperatures and are conducive to die-casting operations to form parts. With crystalline metals, melting temperature and hardness are almost always correlated, which implies that low-melting-temperature metals (such as aluminum, zinc, and magnesium) are soft. BMGs are a rare class of materials that have the hardness of tool steel (Rockwell C 50-60) and yet have melting temperatures that allow them to be cast into nonexpendable molds. Therefore, durable metal parts with high hardness and highly reflective surface finishes can be cast using the economics of casting usually reserved for polymers or lowmelting-temperature metals. Aside from cosmetic components, BMGs also have properties that make them suitable for a range of structural applications. They have ultra-high yield strengths compared with their crystalline constituents, have a $2 \%$ elastic limit prior to yielding, are generally hard, scratch resistant and corrosion resistant, and have moderate toughness. ${ }^{5}$ BMGs do have some notable detractions, mainly a complete lack of ductility, a relatively low fracture toughness for metals, low fatigue limits, low operational temperatures (generally below $500 \mathrm{~K}$ ), and a restriction on sample thickness. To address some of these problems, BMGMCs have been developed, which integrate a soft and ductile crystalline phase into the brittle BMG matrix to improve ductility, toughness, and fatigue. ${ }^{6-9}$ Demonstrations of BMGs and BMGMCs are shown in Figure 1, along with two demonstrations of commercial casting separated by more than a decade. Figure 1a,b shows a BMG ring and ball bearings developed by NASA Jet Propulsion Laboratory. Figure 1c, d shows BMGMC Charpy specimens and a scanning electron microscopic image of a crack growing through a two-phase microstructure. The BMG literature is now largely split between research on monolithic BMGs and BMGMCs, yet the primary consideration with both classes of materials is how they can be processed into usable hardware that exploits their beneficial properties. $^{10}$

\section{NONCONTACT (CONTAINERLESS) MELTING OF GLASS-FORMING ALLOYS}

Commercial processing of BMGs requires that the upper limits of thermophysical properties, such as glass-forming ability and effect of impurities, are known, so that manufactured parts can be compared with a benchmark. Unfortunately, most BMGs are based in alloys systems that are highly reactive in the melt, as with zirconium and titanium BMGs, and are also susceptible to a cascading crystallization event in the presence of impurity inclusions or resulting from interactions with the walls of the containers. Containerless heating, through the use of splat quenching, was fundamental in the development of metallic glasses by Duwez et. al. ${ }^{11}$ at Caltech. Electromagnetic fields were used to simultaneously levitate and melt metal alloys before being splatted between copper anvils, imparting an initial cooling rate of $10^{6} \mathrm{~K} / \mathrm{s}$. Although spat-quenching is a process designed to minimize the possible time for heterogeneous nucleation, it is very difficult to obtain meaningful science from the technique, primarily because heating and levitation are coupled. Although the melting event is containerless, the process of contacting the fluid with the quenching anvils is not, and the large imposed cooling rates make it difficult to discern differences in glassforming ability, as weak and strong glass formers are cooled at the same rate. In 1982, the technique was improved by MC Lee through the use of a drop tower. ${ }^{12}$ Levitated liquids were melted and allowed to freefall through an inert gas, instead of being splatted by copper plates. Cooling was slowed down by using radiation and heat conduction, and 2-3-mm-diameter spheres of Au-BMGs were fully vitrified in the process. Although cooling rates could be slowed using a drop tower, which was useful to investigate better glass-forming alloys, the technique was still limited for studying the thermophysical properties of the liquid (although estimations of heat capacity were obtained). The diameter of droplets that could be vitrified was limited by the physical height of the drop tower and detailed information about the properties of the molten liquid still remained elusive. ${ }^{12}$

In ground-based experiments, the easiest way to achieve a containerless heating/processing condition is through levitation, which can be accomplished through electromagnetic levitation $(E M L)$, acoustical levitation, or electrostatic levitation (ESL). In the EML technique, as discussed above, the effects of gravity must be overcome by electromagnetic forces, which simultaneously couple levitation and melting. This makes undercooling of liquids impossible. Moreover, the levitation forces cause stirring in the melt, which prevents many basic science measurements (e.g., diffusion). EML requires processing in an atmosphere and also produces sample stirring. ESL requires that the forces of gravity are overcome using electrostatic forces. This limits the mass of the levitated liquid and only spherical droplets of approximately 2$3 \mathrm{~mm}$ can be studied. In most ground-based testing, the major problem with containerless melting is the presence of convection flow, a temperature gradient in the liquid that results in gravitydriven and Marangoni convection. Even in the case of good glassforming alloys, which exhibit high viscosities in the liquid, the smallest temperature gradients in the melt cause significant convection.

The application of alternating current pulse heating to microgravity research by Fecht and Johnson ${ }^{13}$ enabled greater precision and freedom of measurement in thermodynamic properties of supercooled melts. This technique uses an EML system, as with ground-based EML systems, except that the microgravity conditions decouple heating from levitation, as the forces required to levitate the spherical sample are much smaller on orbit. The sample can be positioned using a radio frequency quadrupole field in the center of a radio frequency-dipole coil, which provides heating. The sample can be maintained at a constant temperature by modulating the power to the coil to balance the heat loss due to radiation (heat conduction is negligible under ultra-high vacuum conditions). The power coupled to the sample can be correlated to the radio frequency voltage applied, and if the power is coupled in a symmetrical geometry, temperature gradients (and thus Marangoni convection) can be reduced. Temperature can be measured using a wellcalibrated pyrometer, the volume of the sample can be measured directly via video, and heat conduction and contamination can be reduced by utilizing a ultra-high vacuum ( $<10^{-8}$ Torr). Using this technique, noncontact (containerless) calorimetry is then possible on metallic liquids, resulting in high-quality thermophysical data. Now specific heat capacity could be measured on glass-forming alloys in addition to the extent of undercooling, total hemispherical emissivity, thermal conductivity, thermal expansion, surface tension viscosity, and glass-forming ability, among others. In the early 1990s, this equipment was constructed by the German Space Agency (DLR, Deutsches Zentrum für Luft- und Raumfahrt e.V.) and became the Electromagnetic Containerless Processing Facility called TEMPUS (Tiegelfreies ElektroMagnetisches Prozessieren Unter Schwerelosigkeit). ${ }^{1,13}$

\section{MICROGRAVITY DATA OBTAINED UTILIZING TEMPUS}

The TEMPUS facility flew in low Earth orbit three times on NASA's Space Shuttle Columbia during the 1990s. The inaugural flight was in 1994 on the second International Microgravity Laboratory mission (IML-2) as part of STS-65 (see NASA's Mission 

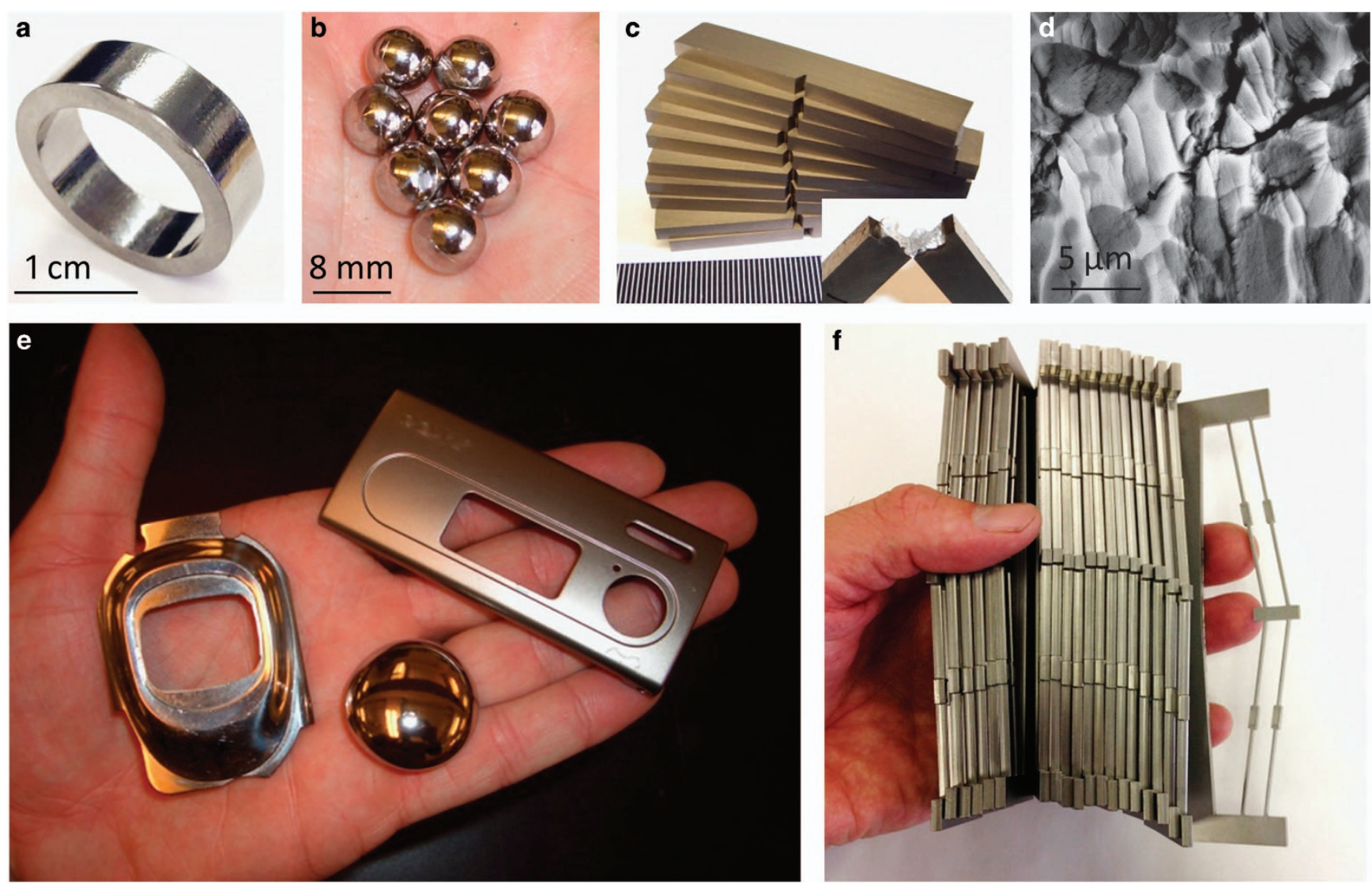

Figure 1. Processing BMGs and BMG matrix composites (BMGMCs) and commercial fabrication. (a) A Ti-based BMG cast into a 25-mm diameter ring using advanced copper-mold casting techniques. (b) A 8-mm-diameter ball bearings cast from a BMG. (c) Several Charpy impact specimens of a Zr-Ti-Nb-based BMG matrix composite and one that has been fractured, demonstrating high toughness. (d) SEM micrographs of cracks propagating through a Zr-Ti-Nb-based BMG matrix composite showing extensive damage accumulation. The darker phases are soft crystalline dendrites grown in situ from the liquid. The two-phase microstructure of BMGMCs leads to extensive room temperature tensile ductility and improved Charpy impact toughness. All of the images in a-d were fabricated by the current authors at NASA JPL and Caltech. Details about the alloys in this figure can be found in refs 6-10. (e) A BMG die-casting technique was adopted by Liquidmetal Technologies, Rancho Santa Margarita, CA, to form electronic casings out of BMGs. (f) Next-generation BMG parts fabricated in 2013 through a collaboration between NASA JPL, Liquidmetal Technologies, Visser Precision Casting and Materion. Using new casting techniques, high-quality and tough BMG parts can be produced through injection casting. The parts shown are BMG compliant mechanisms (jointly developed by NASA JPL and Brigham Young University) showing mass production potential. All images are provided by the current authors. BMG, bulk metallic glass; JPL, Jet Propulsion Laboratory; NASA, National Aeronautics and Space Administration; SEM, scanning electron microscopy.

Archives, http://www.nasa.gov/mission_pages/shuttle/shuttlemissions/ archives/sts-65.html). The alternating current modulation technique was utilized on several alloys during IML-2, including pure $Z$, $\mathrm{Zr}_{76} \mathrm{Ni}_{24}, \mathrm{Zr}_{64} \mathrm{Ni}_{36}, \mathrm{Ni}_{60} \mathrm{Nb}_{40}$, and $\mathrm{Zr}_{72} \mathrm{Fe}_{28}$ (at least three of these alloys, $\mathrm{Zr}_{76} \mathrm{Ni}_{24}, \mathrm{Zr}_{64} \mathrm{Ni}_{36}$, and $\mathrm{Ni}_{60} \mathrm{Nb}_{40}$ can be formed into metallic glasses using rapid solidification techniques). During the flight, the TEMPUS facility experienced problems with sample stability, which limited processing times, and with undercooling due to contamination. Despite this, a number of thermophysical properties were measured, including enthalpy of fusion and crystallization, specific heat, total hemispherical emissivity, and effective thermal conductivity. ${ }^{14-17}$ In the experiments, 8-mm-diameter spheres were heated by a $400-\mathrm{kHz}$ radio frequency coil and positioned with a $200-\mathrm{kHz}$ quadrupole field. The heating power was sinusodially modulated with frequency, $\omega$, and amplitude $P_{\omega}$, resulting in a phase-shifted modulated temperature response with amplitude $\Delta T_{\omega}$. Two relaxation times, $\tau_{1}$ and $\tau_{2}$, representing the timescales of radiative temperature relaxation in response to the modulation, were measured from the experiments. ${ }^{15}$ The combination of the alternating current calorimetry and the relaxation time measurements, allowed for precise measurements of thermophysical properties using the relations:

$$
\begin{aligned}
& \Delta T_{\omega}=f(\omega) \frac{P_{\omega}}{C_{P} \omega} \\
& \tau_{1}=\frac{C_{P}}{4 A \sigma \varepsilon T_{0}^{3}} \\
& \tau_{2}=\frac{3 C_{P}}{4 \pi^{3} K R}
\end{aligned}
$$

where $f(\omega)$ is a correction function, $C_{P}$ is the heat capacity, $A$ is the surface area, $R$ is the radius, $k$ is the thermal conductivity, $\varepsilon$ is the total hemispherical emissivity, $\sigma$ is the Stefan-Bolzmann constant, and $T_{O}$ is the bias temperature. Figure 2 shows data obtained from TEMPUS on IML-2 on the binary glass-forming alloy $\mathrm{Zr}_{64} \mathrm{Ni}_{36}{ }^{14,16}$ Figure 2a shows a metallic sphere in the TEMPUS coil and Figure $2 \mathrm{~b}$ shows tiles from a video of a sample being melted in the TEMPUS apparatus. Figure $2 \mathrm{c}$ is a plot of electrical resistivity of the 

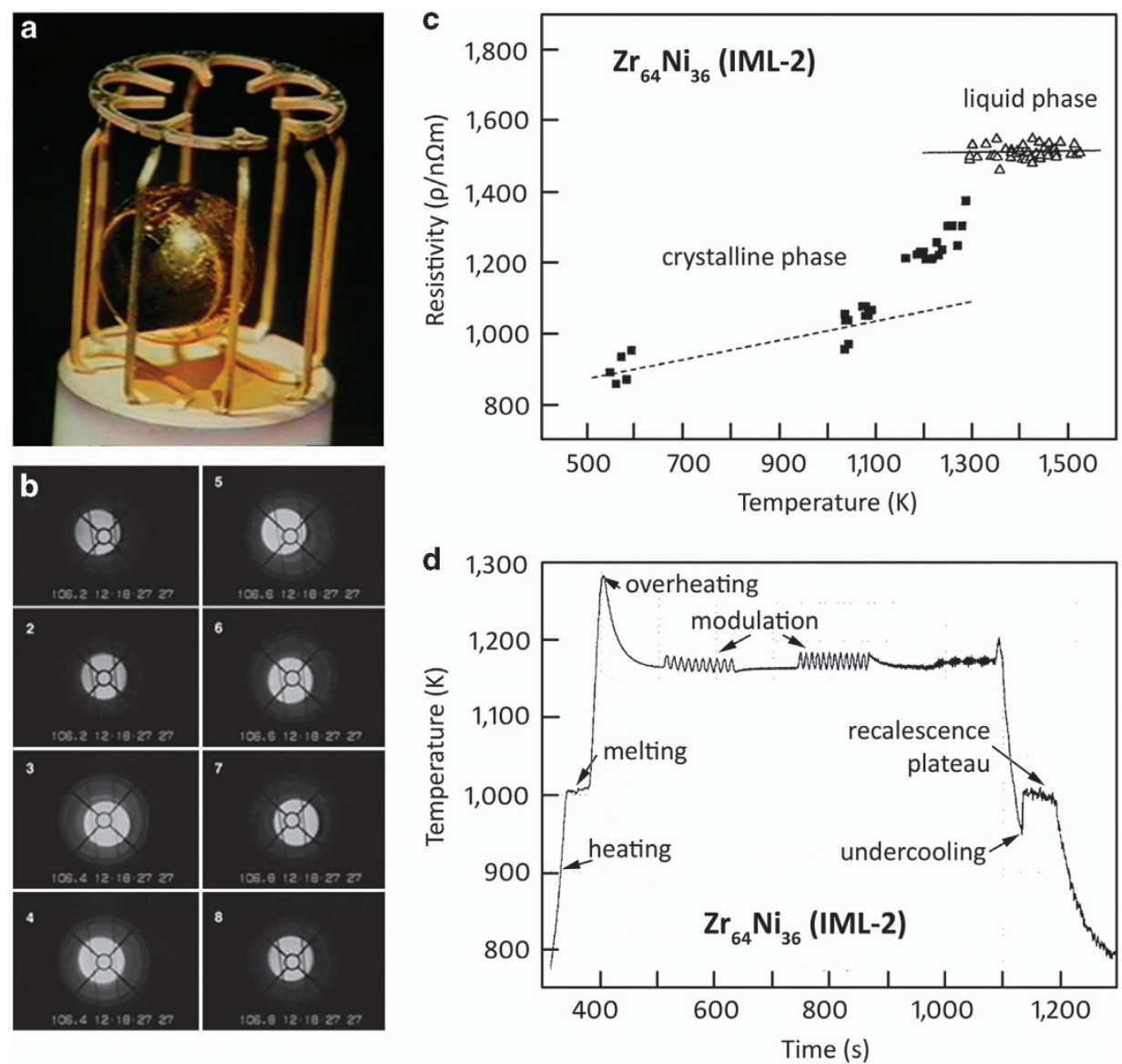

Figure 2. Microgravity metal processing on IML-2. These images and data were collected during IML-2 during the 1994 STS-65 mission on the Space Shuttle Columbia. (a) A 8-mm-diameter metallic sphere trapped in a sample containment device on TEMPUS and (b) tiles from a video showing the melting and positioning of a metal alloy. Images from NASA MSFC. (c and d) shows processing data on a Zr-Ni alloy in microgravity. (c) Resistivity measurements on the crystalline phase and liquid phase of the glass-forming alloy were measured. (d) A typically processing history for an alloy on TEMPUS using the alternating current-modulation technique. The alloy is heated above the melting temperature and then held isothermally using alternating current modulation. After a prescribed holding period, the heating source is removed and the alloy is allowed to cool through radiation. The extent of undercooling can then be observed using the cooling profile. Data were provided by H Fecht and adapted from ref. 16. IML-2, International Microgravity Laboratory mission; MSFC, Marshall Spaceflight Center; NASA, National Aeronautics and Space Administration; TEMPUS, Tiegelfreies Elektro-Magnetisches Prozessieren Unter Schwerelosigkeit.

glass-forming alloy $\mathrm{Zr}_{64} \mathrm{Ni}_{36}$ measured in both the crystalline and liquid state using the IML-2 spacelab equipment. ${ }^{16}$ Owing to the lack of a high-resolution camera on IML-2, it could not be determined whether the liquid phase of the alloy exhibited a negative temperature coefficient of the electrical resistivity; however, this problem was later addressed on a future mission. Figure $2 \mathrm{~d}$ shows a temperaturetime profile for processing a $\mathrm{Zr}_{64} \mathrm{Ni}_{36}$ specimen in microgravity, which includes melting, overheating, alternating current modulation, relaxation times, recalescence, and undercooling. ${ }^{14}$ These data were used to determine the specific heat in the undercooled melt.

The TEMPUS facility flew twice more on Columbia, once in April 1997 on STS-83 and once in July 1997 on STS-97, as part of the Microgravity Science Laboratory-1 (MSL-1) (see NASA's Mission Archives, http://www.nasa.gov/mission_pages/shuttle/shuttlemis sions/archives/sts-83.html http://www.nasa.gov/mission_pages/ shuttle/shuttlemissions/archives/sts-94.html). STS-83 was cut short due to concerns about one of the three space shuttle fuel cells but was quickly reflown the same year. Compared with IML-2, the data obtained as part of the two MSL-1 flights using TEMPUS was extraordinary. Contamination problems experienced on IML-2 were corrected and TEMPUS produced the highest temperature $(2273 \mathrm{~K})$ and the largest undercooling $(340 \mathrm{~K})$ ever achieved in space. Ten different studies on undercooled metallic melts were performed by scientists from Germany and the United States, resulting in a large quantity of fundamental data. ${ }^{18}$ Among these experiments, viscosity, thermal expansion, and surface tension were measured on the glass-forming alloy $\mathrm{Pd}_{76} \mathrm{Cu}_{6} \mathrm{Si}_{16}{ }^{18-20}$ Specific heat in the undercooled liquid of two BMGs, $\mathrm{Zr}_{65} \mathrm{Al}_{7.5} \mathrm{Cu}_{17.5} \mathrm{Ni}_{10}$ and $\mathrm{Zr}_{60} \mathrm{Al}_{10} \mathrm{Cu}_{18} \mathrm{Ni}_{9} \mathrm{Co}_{3}$, were measured, and the specific heat of two BMGs, $\mathrm{Ti}_{34} \mathrm{Zr}_{11} \mathrm{Cu}_{47} \mathrm{Ni}_{8}$ (Vitreloy 101) and $\mathrm{Zr}_{57} \mathrm{Nb}_{5} \mathrm{Ni}_{12.6} \mathrm{Al}_{10} \mathrm{Cu}_{15.4}$ (Vitreloy 106), were measured. ${ }^{18} \mathrm{~A}$ selection of data obtained on undercooled glass-forming liquids on MSL-1 are shown in Figure 3. The surface tension as a function of temperature for $\mathrm{Pd}_{76} \mathrm{Cu}_{6} \mathrm{Si}_{16}$ is shown in Figure $3 \mathrm{a}$, whereas Figure $3 \mathrm{~b}$ shows the viscosity as a function of temperature measured by oscillating at several points during the undercooling. An undercooling experiment from a $\mathrm{Zr}_{65} \mathrm{Al}_{7.5} \mathrm{Cu}_{7.5} \mathrm{Ni}_{10}$ BMG-forming alloy is shown in Figure $3 \mathrm{C}$ and a normalized heat capacity is shown for the BMG Vitreloy 106 in Figure 3d, demonstrating a discontinuity just above the liquidus, which likely represents a phase change due to the changing emissivity of the sample. ${ }^{16}$

Compared with IML-2, where predominantly binary alloys were investigated, MSL-1 provided data on a wide variety of multicomponent alloys, notably Vitreloy 106, one of the most commercially and scientific relevant BMGs to date. Vitreloy 106, a five-component zirconium-based BMG, is one of the best 
a

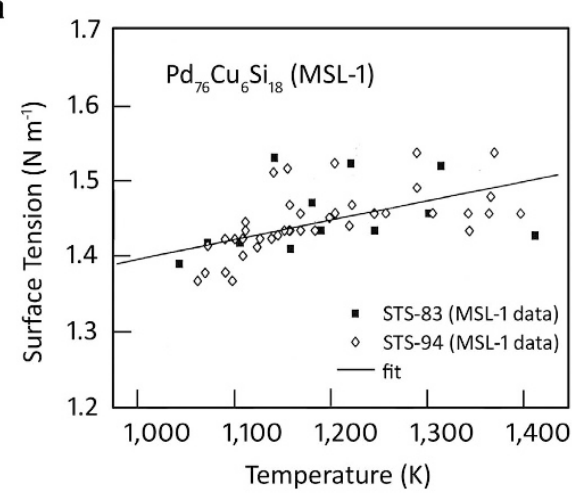

c

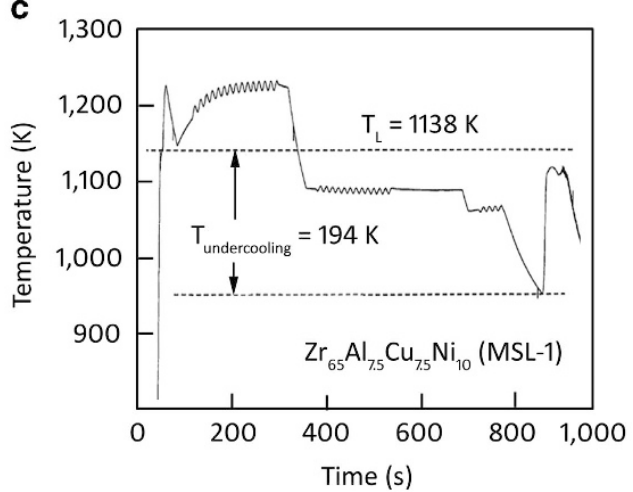

b

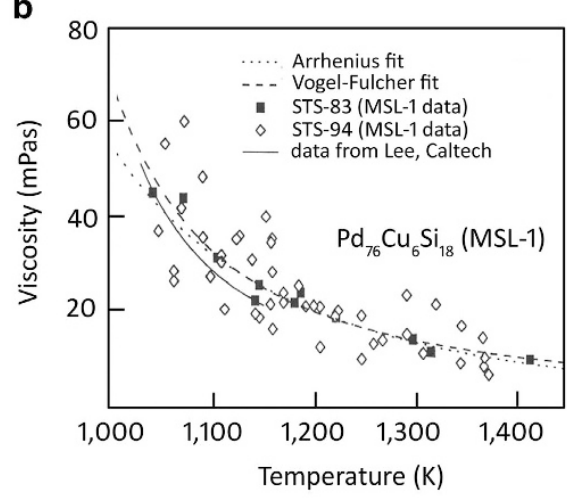

d

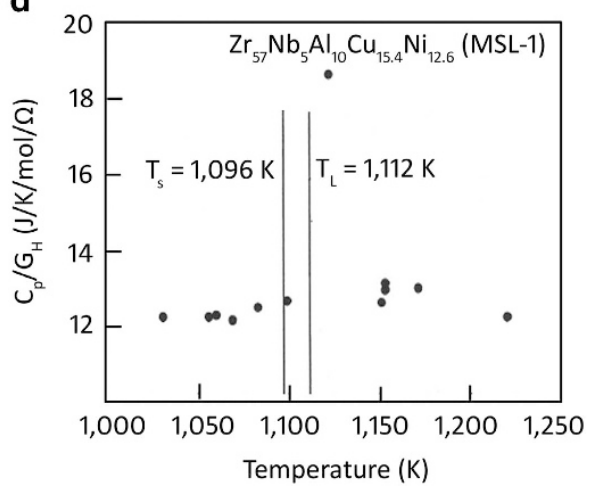

Figure 3. Microgravity processing of glass-forming alloys on MSL-1. Data taken from a variety of microgravity experiments utilizing the TEMPUS facility during the 1997 STS-83 and STS-97 MSL-1 mission on the Space Shuttle Columbia. (a) Surface tension versus temperature measured on the glass-forming alloy $\mathrm{Pd}_{76} \mathrm{Cu}_{6} \mathrm{Si}_{18}$ and (b) viscosity versus temperature measured through drop oscillation on the same alloy comparing data obtained on MSL-1 versus data collected on Earth. (c) Measurements of undercooling in a $\mathrm{Zr}_{65} \mathrm{Al}_{7.5} \mathrm{Cu}_{7.5} \mathrm{Ni}_{10}$ glass-forming alloy utilizing the alternating current-modulation technique. (d) Specific heat versus temperature measurements on the best glass-forming alloy studied during the TEMPUS program, Vitreloy $106\left(\mathrm{Zr}_{57} \mathrm{Nb}_{5} \mathrm{AL}_{10} \mathrm{Cu}_{15.4} \mathrm{Ni}_{12.6}\right)$, showing an anomaly in specific heat near the liquidus temperature. The data were provided by H Fecht and WL Johnson. MSL-1, Microgravity Science Laboratory-1; TEMPUS, Tiegelfreies ElektroMagnetisches Prozessieren Unter Schwerelosigkeit.

glass-forming alloys based in practical elements. This alloy, and similar variations, has found widespread use in the BMG literature and commercial industry, due to its glass-forming ability and its lack of deprecated beryllium, a constituent in the most widely used BMG, Vitreloy $1 .^{21}$ In fact, a Vitreloy 106 variant plate became the first BMG to be a component on a spacecraft in 2001 as part of NASA's Genesis mission, where it was used as a sample collector for solar wind (see the following section for more information). On the basis of the success of TEMPUS, further experiments on glassforming alloys were planned for microgravity in the late 1990s. A NASA program entitled Properties of Undercooled Glass-forming Alloys was planned to study transport and atomic diffusion on metallic glasses, but was never flown due to the loss of the Space Shuttle Columbia in 2003. Nevertheless, microgravity metalprocessing experiments continued to be funded by NASA/ European Space Agency and other space agencies. Extended periods of reduced gravity for metal processing have become available on parabolic flights (20 s of microgravity) and sounding rockets (such as the TEXUS sounding rockets, which were used to achieve up to $320 \mathrm{~s}$ of microgravity). Long-duration microgravity experiments have also been housed on the ISS in multi-user facilities. For example, ThermoLab is an international ISS program involving several space agencies, including NASA, European Space Agency, DLR, Japan Aerospace Exploration Agency, and Canadian Space Agency, among others. This program will investigate viscosity, surface tension, emissivity, specific heat, electrical and thermal conductivity, and other calorimetric properties. Details about these efforts can be seen in $\mathrm{H}-\mathrm{J}$ Fecht, et. al, 'Laboratory
Science with space data, accessing and using space-experiment data', Springer (2011).

\section{BMGs FLY ON GENESIS TO COLLECT SOLAR WIND}

The BMG Vitreloy 106 is an excellent example of the rapid adoption of metallic glasses for space applications. Developed at Caltech in 1995 under funding from the US Department of Energy, Vitreloy 106 was immediately notable because of its greater than $1-\mathrm{cm}$ casting diameter, without the presence of $\mathrm{Be}$, which was a trademark of the Vitreloy series of alloys developed in 1993, also at Caltech. ${ }^{21-23}$ Just 2 years after its development, a Vitreloy 106 variant was flown on TEMPUS as part of MSL-1, where specific heat measurements in the undercooled liquid state were measured (see Figure 3$){ }^{18}$ and only 6 years after its development, the BMG was integrated into NASA's Genesis mission as a solar wind collector. $^{24}$ In 2001, the ESL at NASA Marshall Spaceflight Center was used to show that a slight variant of Vitreloy 106, $\mathrm{Zr}_{58.5} \mathrm{Nb}_{2.8} \mathrm{Cu}_{15.6} \mathrm{Ni}_{12.8} \mathrm{Al}_{10.3}$ (called Vitreloy 106a), exhibited a critical cooling rate of $1.75 \mathrm{~K} / \mathrm{s}$, only about twice as large as Vitreloy $1 .^{25}$ This alloy was selected for Genesis because it was the best non-beryllium glass-forming alloy and could be etched uniformly (Genesis had an interest in detecting light elements in solar wind and thus beryllium needed to be excluded from the alloy). Launched in August 2001, Genesis was the first NASA mission since the Apollo program of the 1960-70s to return material to Earth, and was the first mission to return material from beyond the Moon's orbit. The sample collectors, which were 

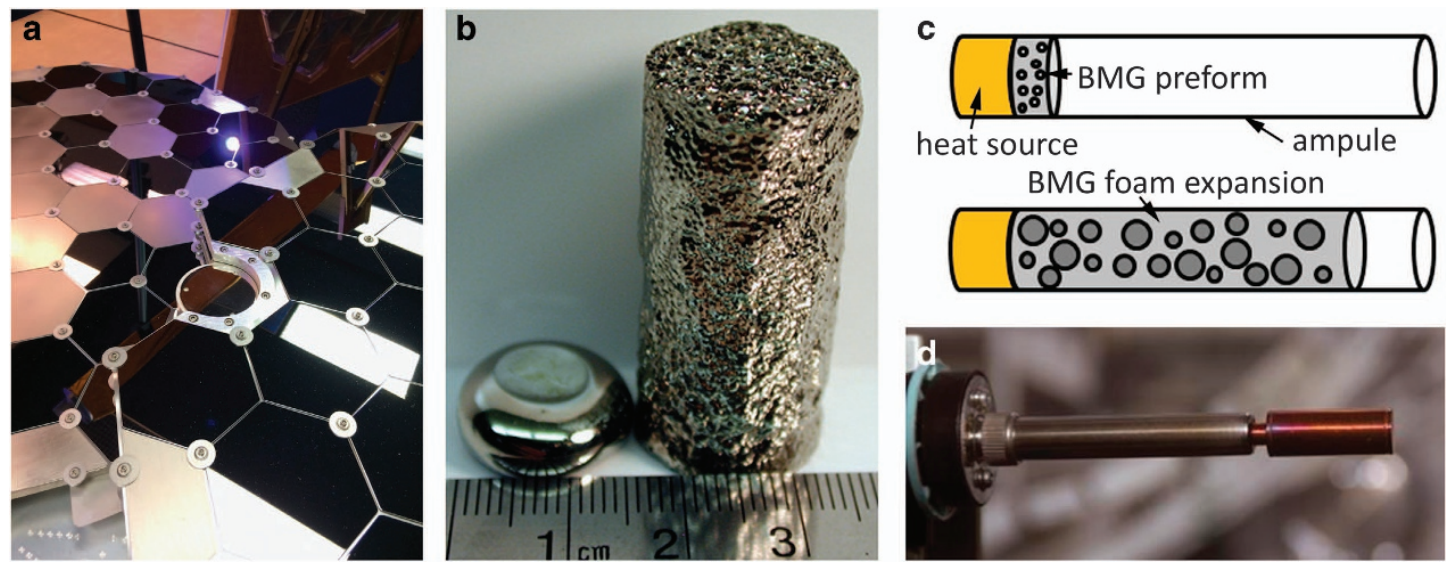

Figure 4. Genesis BMG solar collector and BMG foam fabricated on the orbit. (a) The flight mock-up of the Genesis solar wind collector on display at NASA's JPL, Pasadena CA. The circular sample in the center of the image was the location of the Vitreloy 106 BMG. The BMG panel was one of the few that survived the crash-landing of Genesis in the desert and was later used in several high-profile publications. (b) A Pdbased BMG foam fabricated through thermoplastic expansion compared with an ingot of the same alloy and mass, but with $0 \%$ porosity. (c) A schematic of how the BMG foam was fabricated on orbit (on the ISS) using an ampule and heat provided by an astronaut's soldering gun. The actual experiment is shown in d. Images are provided by MD Demetriou. BMG, bulk metallic glass; ISS, International Space Station; JPL, Jet Propulsion Laboratory; NASA, National Aeronautics and Space Administration.

designed to be flown through solar wind, were hexagonally shaped targets of a variety of materials, including a Vitreloy 106a BMG. The samples were designed to be etched off using different chemicals, allowing a variety of compositions from the solar wind to be detected. The BMG was used because it could be etched very homogeneously in nitric acid, due to the lack of grain boundaries in the amorphous microstructure. The Genesis mission provided one the finest moments in the history of BMGs when it crash-landed in the Utah desert in 2004, due to a faulty parachute. The BMG sample was one of the only targets that survived the impact and was later used to answer fundamental questions about solar wind composition (see refs 26-30). Figure 4a shows the flight mock-up of Genesis on display at NASA's Jet Propulsion Laboratory, Pasadena, CA.

\section{ON-ORBIT MANUFACTURING OF BMG FOAMS}

BMG processing research was performed in microgravity in 2004 with thermoplastic foaming of a $\mathrm{Pd}_{40} \mathrm{Ni}_{40} \mathrm{P}_{20}$ BMG on-orbit (see NASA's International Space Station Research \& Technology Page http://www.nasa.gov/mission_pages/station/research/experiments/ 259.html). ${ }^{31}$ Although the intent of the experiments were science driven, the authors unknowingly performed one of the first demonstrations of on-orbit metal manufacturing, a concept that has recently become one of the most visible objectives of future ISS research. For example, NASA Langley Research Center and commercial companies, such as Made in Space, have endeavored to put three-dimensional metal printers on the ISS to perform on-orbit manufacturing (see, for example, NASA's Technology Features Page: Electron beam freeform Fabrication http://www. nasa.gov/topics/technology/features/ebf3.html) (see, for example, Made in Space http://www.madeinspace.us). The BMG foaming experiments in 2004 were actually designed to demonstrate the benefits of using BMG foams on Earth, as opposed to aluminum foams, for example. In their respective processing windows for foam formation, BMGs exhibit a more than 10 orders of magnitude higher viscosity than aluminum, which implies that the sedimentation velocity for the bubbles, which are used to make the foam, are on the order of $1 \mathrm{~nm} / \mathrm{s}$ in the BMG versus $1 \mathrm{~m} / \mathrm{s}$ in aluminum. Therefore, a BMG foam produced in gravity is not markedly affected by sedimentation, which is a major processing challenge with crystalline metal foams. The microgravity research on the ISS was therefore aimed at demonstrating that BMG foams could be fabricated on Earth, without the negative effects of bubble sedimentation that occurs in the more commonly used foams.

The foaming experiment proceeded by first preparing a 1.4-g amorphous foam precursor, which was incorporated with a micron-sized bubble of $\mathrm{Ar}$ gas at $1 \mathrm{~atm}$. The precursors were sealed in a copper ampoule with an initial volume 12 times larger than the volume of the amorphous foam precursor. Utilizing an existing soldering tip (already a component of the astronaut's tool kit), the ampoule was heated to $633 \mathrm{~K}$ and held for $5 \mathrm{~min}$. The BMG was subsequently heated into its supercooled liquid region, above its glass transition temperature, and allowed to free-expand into the copper ampule. This was similar to the way that the same BMG foams were prepared on Earth. ${ }^{32,33}$ A sample of a Pd-based BMG foam is shown in Figure $4 \mathrm{~b}$ alongside a non-porous sample of the same mass. Figure $4 c$ shows a schematic of the processing of the BMG foam in microgravity, and Figure $4 d$ shows the copper ampule used for foam processing on the ISS. Images are from MD Demetriou and NASA Marshall Spaceflight Center.

The BMG foaming experiments were an impressive demonstration of on-orbit metal manufacturing. A small volume BMG preform was heated (using available on-orbit techniques) and was allowed to free-expand to 10 times its initial volume. The relatively low temperature associated with thermoplastic foam formation in BMGs makes the process accessible to future space-based manufacturing applications. For example, BMG cellular structures have already been demonstrated to have excellent performance as spacecraft shields for orbital debris protection. ${ }^{34,35}$ Having a material that can be packaged into a small launch volume and then be deployed on-orbit, to either fill a mold or in free expansion, while still retaining high-strength and excellent energy-absorbing capacity, is a major advancement for space manufacturing.

\section{GROUND-BASED EXPERIMENTATION ON BMGS USING ESL}

One of the major reasons why BMG development occurred so rapidly during the 1990s was the implementation of both groundbased and space-based experimentation. In parallel with microgravity investigations that were being planned for TEMPUS, NASA funding resulted in the development of ground-based ESL 
equipment at NASA's Jet Propulsion Laboratory in $1993 .^{36}$ As discussed previously, ground-based EML systems require that sample levitation and processing are coupled and eddy currents induced in the samples prevent nonelectrically conductive materials from being levitated. In contrast, ESL uses feedback control to levitate a sample between parallel electrode plates, where the gravitational body force of the sample can be offset with charge induced from an applied voltage. In the ESL, sample heating and levitating are decoupled, allowing for external heating (e.g., through an arc lamp or laser) to be used for melting and solidification processes. It also provides an open view of the sample so that noncontact diagnostics, such as thermal analysis and video can be performed in situ during processing. Samples of metal alloys, semiconductors, and insulators can all be melted by $E S L$, whereas only electrically conductive materials can be processed by EML.

Although the ESL could only levitate BMG samples up to $3 \mathrm{~mm}$ in diameter, compared with the 8- $\mathrm{mm}$ samples used on TEMPUS, it offered a wide assortment of advantages for processing BMGs that was critical to their commercial implementation. The most obvious advantage was that the ESL could be used to generate data on a wide number of alloys at a small fraction of the cost of performing the same experiment in microgravity. The ESL was originally equipped with a xenon arc lamp to provide heating but was later outfitted with tetrahedral laser heating, to reduce thermal gradients. Ultra-high vacuum conditions of $5 \times 10^{-8} \mathrm{mtorr}$ were achieved to prevent sample contamination and advanced feedback control was used for precise sample positioning (for specific volume and surface tension experiments). For these reasons, the Jet Propulsion Laboratory facility was later renamed the High-Temperature, High-Vacuum ElectroStatic Levitation facility or HTHVESL. In the early 1990s, the primary focus of the HTHVESL was to study the behavior of a newly created BMG, Vitreloy $1\left(\mathrm{Zr}_{41.2} \mathrm{Ti}_{13.8} \mathrm{Cu}_{12.5} \mathrm{Ni}_{10.0} \mathrm{Be}_{22.5}\right)$, which was touted for its greater than $25-\mathrm{mm}$ casting diameter. Vitreloy 1, which would later become the foundation for the US BMG commercial industry, was not allowed to be part of the NASA microgravity program, primarily because it contained 22.5 at. \% of beryllium. The HTHVESL was a ground-based system that could be operated without endangering the breathing environment for astronauts, which allowed it to be used to develop the fundamental thermophysical properties for Vitreloy 1 , which were ultimately used as parameters for industrial processing.

Many of the first publications using the Jet Propulsion Laboratory HTHVESL were studies of the glass formation of the alloy Vitreloy 1 , which utilized the simulated microgravity effects of ESL for containerless processing. In 1994, the system was used to vitrify 3-mm-diameter spheres of Vitreloy 1, demonstrating that the critical cooling rate for glass formation was $0.9-1.2 \mathrm{~K} / \mathrm{s}$, making the alloy the best known glass former of the time. ${ }^{37}$ Critically, the experiments also showed that when the sample was held above its melting temperature for a sufficient time to dissolve oxides, it could be cooled at a slower critical cooling rate. These data were extremely useful for developing commercial die-casting equipment, where knowledge about crystallization was used to 'overheat' glass-forming liquids prior to casting. The HTHVESL was subsequently used for a plethora of studies of Vitreloy 1, and other BMGs, to develop time-temperature transformation diagrams, ${ }^{38}$ develop a critical cooling rate to bypass crystallization, $^{39}$ study the effects of contamination and temperature on cooling rate, ${ }^{40}$ decomposition, and crystallization of BMGs, ${ }^{41}$ specific volume, surface tension, and viscosity, ${ }^{38}$ continuous heating and cooling diagrams, ${ }^{42}$ and history-dependent crystallization, ${ }^{39}$ among many others. The HTHVESL technology was also adopted by NASA's Marshall Spaceflight Center in Huntsville, Alabama, where significant upgrades have been made to improve scientific output. The HTHVESL at Marshall Spaceflight Center was utilized in 1999 to determine the glass-forming ability of Vitreloy 106a, the first non-beryllium-bearing BMG to fully vitrify under the radiative cooling conditions of the apparatus. ${ }^{25}$ The HTHVESL continues to be used today to study the formation and processing of dendrites in BMGMCs. Some details about these experiments are shown in Figure 5. The HTHVESL has been used recently by the current authors under NASA funding to study dendrite solidification in BMGMCs. ${ }^{43}$ Figure $5 \mathrm{~d}$ shows a typical heating and cooling curve for a BMGMC, which looks similar to data obtained from TEMPUS. The ESL was used to semi-solidly process the BMGMCs to study coarsening of the microstructures. The ESL has also been used to determine the first measurements of viscosity and surface tension of BMGMCs, shown in Figure $5 e, f^{43}$

\section{COMMERCIAL PROCESSING OF BMGs}

Commercial processing of metallic glasses is now decades old, first introduced by what is today Allied MetGlas for use in magnetic transformer coils (www.metglas.com). Shortly after the development of Vitreloy 1 at Caltech in 1992, Amorphous Technologies International of Laguna Niguel, CA, was launched to commercialize the new field of BMGs, those alloys that can be formed into amorphous parts at a thickness in excess of $1 \mathrm{~mm}$. Amorphous Technologies International later became Liquidmetal Technologies (www.liquidmetal.com), which introduced BMGs to the commercial market with a daughter company Liquidmetal Golf, in 1997. The trade named Liquidmetal Alloys or LM, which were made largely from Vitreloy 1, were sold as high-performance golf clubs and were fabricated utilizing die-casting technology. In the early 2000s, Liquidmetal launched a product line of components for electronic casings for cell phones, including materials that were integrated into devices for Motorola, Samsung, LG, Sandisk, and Apple. In 2010, Liquidmetal's intellectual property was acquired by Apple, which strongly suggests that the material will become a mainstay product in the consumer electronics industry (see, for example, Why is Apple Licensing Liquidmetal? By Jason Ogrady. The Wall Street Journal, 9 August 2010).

In addition to Liquidmetal, several other commercial companies have explored BMGs as products. Among them, Howmet Corporation (Whitehall, MI), fabricated the largest known plates of Vitreloy 1 as part of their 'Metal Mold Division,' in the late 1990s. More recently, Materion (www.materion.com) has begun commercial fabrication of BMG feedstock, Visser Precision Casting (www.visserprecisioncast.com) has produced BMG products under contract and a new Caltech start-up, Glassimetal Technologies, has explored a novel fabrication technology for BMGs. The Japanese group of Prof A Inoue has also been commercializing BMGs in Japan since the 1990s. ${ }^{44,45}$

Despite the two decades worth of effort in commercializing BMGs, the materials have still not found their way into widespread commercialization. The reasons for this can largely be traced back to the experiments that were performed in microgravity on TEMPUS and on the HTHVESL. All zirconium- and titanium-based BMGs are extremely reactive when in contact with crucibles or oxygen, are largely affected by impurities, have a historydependent crystallization that must be overcome to reliably fabricate components, and have fracture toughness that is highly coupled to processing and composition. Early commercial production was plagued with problems stemming from lowquality material, interactions with graphite die-casting crucibles, unknown temperature effects, mold-filling problems, and poor vacuum. ${ }^{10,46}$ The early business model for the commercialization of BMGs was based on replacing plastics in electronic casings, requiring BMGs to compete with plastics on cost. This model emphasized rapid fabrication over mechanical properties, which was ultimately the downfall of the industry. Early Vitreloy 1 parts were made by die-casting high-oxygen content billets in graphite crucibles before being cast into steel molds. Rapid part fabrication caused flow lines on many parts from turbulence in the liquid, 

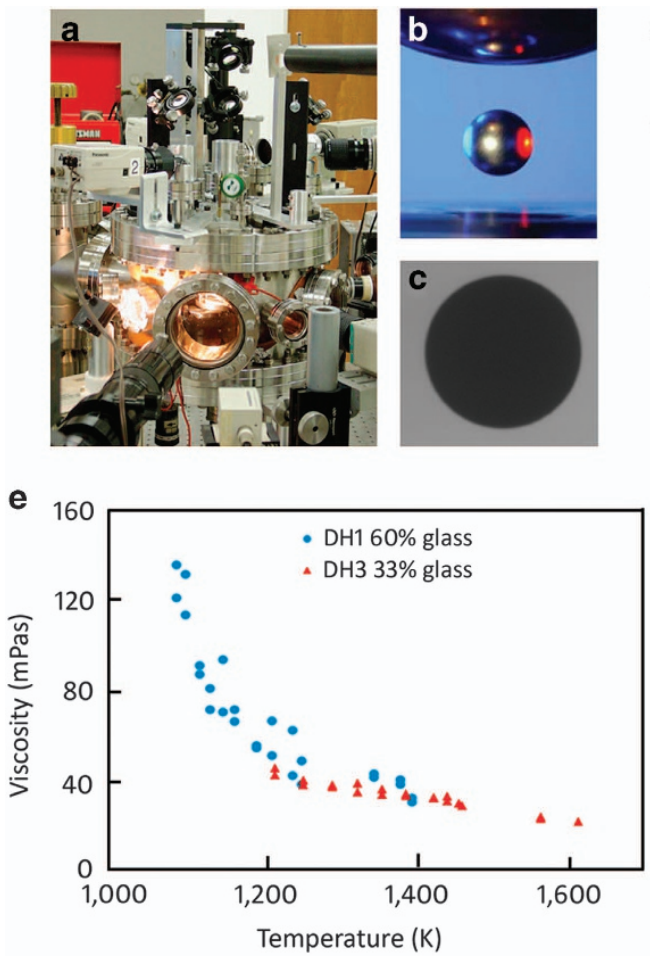
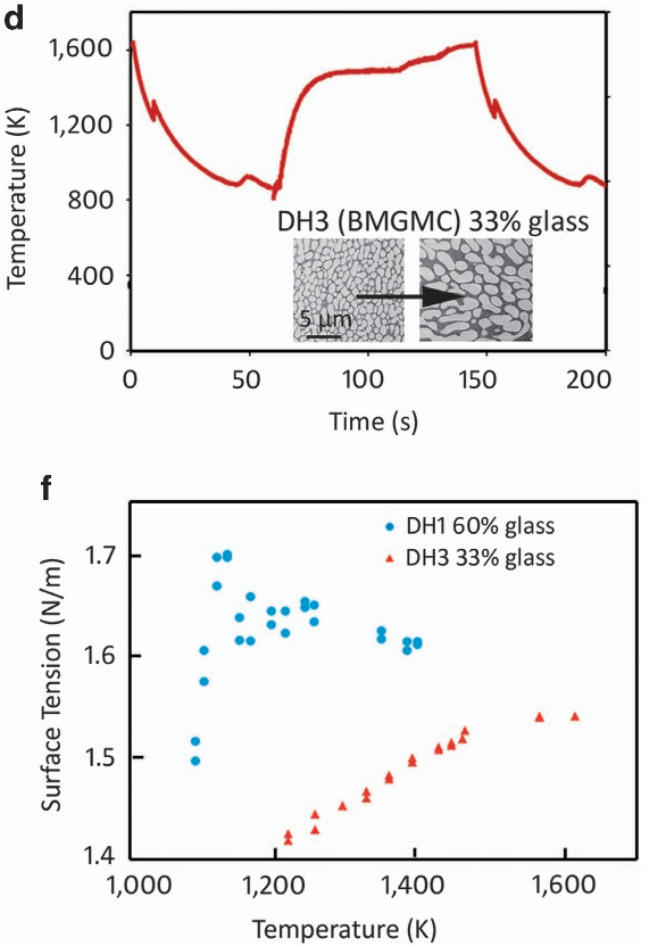

Figure 5. Containerless processing using the JPL/Caltech HTHVESL. (a) Image of an HTHVESL. By performing experiments terrestrially, alloys unable to be tested on orbit can be observed in a simulated microgravity environment. (b) An image of a levitated 3-mm-diameter sphere of metal. The ESL decouples melting and heating, which allows for the replication of microgravity conditions on Earth. Image from NASA MSFC. (c) A two-dimensional shadow of a molten ingot being processed in the HTHVESL at Caltech, which is used for measurements of specific volume and radius change. (d-f) Data obtained on two BMGMCs using the HTHVESL to study dendrite growth and semisolid processing in a containerless environment. (d) A typically heating and cooling profile from the ESL looks nearly identical to profiles obtained on orbit using the TEMPUS facility. Dendrite coarsening in the HTHVESL by performing an isothermal hold is shown in the insets. (e) Viscosity data obtained on BMGMCs above the liquidus and (f) surface tension as a function of processing temperature for two BMGMCs. All data are provided by the current authors. BMGMC, bulk metallic glass matrix composite; ESL, electrostatic levitation; HTHVESL, High-Temperature, High-Vacuum ElectroStatic Levitation facility; JPL, Jet Propulsion Laboratory; MSFC, Marshall Spaceflight Center; NASA, National Aeronautics and Space Administration.

crystallization, and brittleness were common among cast parts. ${ }^{46}$ In a testimony to the glass-forming ability of Vitreloy 1 , billets of material could be recycled over and over and yet could still be processed into amorphous parts, albeit parts containing more and more oxygen. Only years later did the effect of oxygen content on the fracture toughness of BMGs become well known. For example, early BMG golf drivers were well known for having excellent performance, but would often fracture after a few hundred hits. The microgravity and HTHVESL data that were obtained stressed the importance of understanding how processing affects the formation and properties of BMGs. The materials need to be made with high-purity elements free of oxygen, they need to be produced under inert gas environments, they must be processed at a sufficiently high temperature to erase crystallization history, and they must be fabricated in molds using the least amount of interaction possible. By following these rules, both glass-forming ability and fracture toughness could be markedly improved. In the years since the first microgravity experiments, many studies have shown the effect of processing on mechanical properties.

\section{CURRENT TRENDS IN BMG PROCESSING}

Starting around 2000 , as more information about the fundamental properties of BMGs was discovered, it became apparent why the first attempts at commercializing BMGs floundered. The scientific literature on BMGs shows this trend, with papers increasingly discussing how to improve the toughness and ductility of metallic glasses, compared with papers on improving glass-forming ability, which dominated literature in the 1990s. A number of advances in the mechanical properties of BMGs were developed during this time period, including the ability to thermoplastically form $\mathrm{BMGs}^{47,48}$ improving properties using composition, ${ }^{49}$ blow molding, $^{50}$ injection molding, ${ }^{46}$ rapid capacitive discharge, ${ }^{51}$ semi-solid processing of BMGMCs, ${ }^{8,9}$ nano forming, ${ }^{52}$ among many others. From a processing and commercialization perspective, the biggest advances related to limiting contamination in the BMG melt prior to casting. The poor-vacuum, graphite crucibles of the die-casting days were largely replaced with inert environments and cold-wall (or low-reaction) crucibles. ${ }^{46}$ Converted plastic injection-molding machines with cold-wall crucibles are now being investigated for commercial fabrication. In addition, a new rapid capacitive discharge technology has been commercialized in a new start-up, Glassimetal Technologies. The process involves volumetric heating of BMGs using a capacitive discharge, which eliminates the use of melting crucibles. ${ }^{51}$ In summary, BMGs have found a resurgence in commercial interest, largely driven by the now proven understanding of how properties are affected by processing. Details about recent trends in BMG processing can be found in ref. 10, a review article by one of the current authors.

\section{CURRENT MICROGRAVITY RESEARCH ON BMGMCS}

Current experiments on BMGs are being planned for the ISS, based on new equipment that was recently installed by 
a

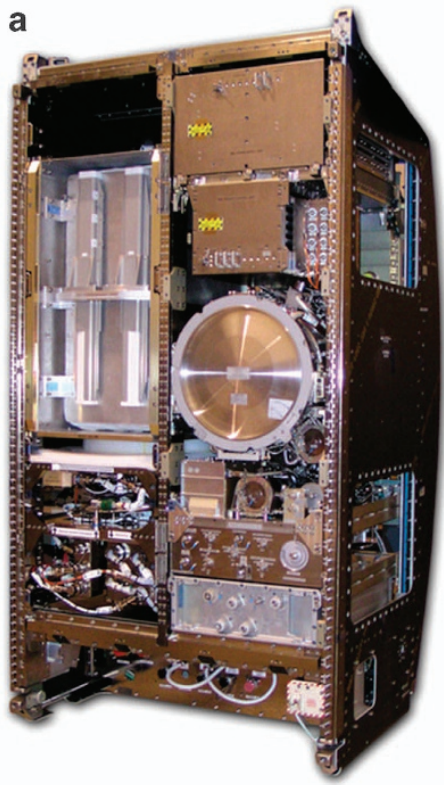

b

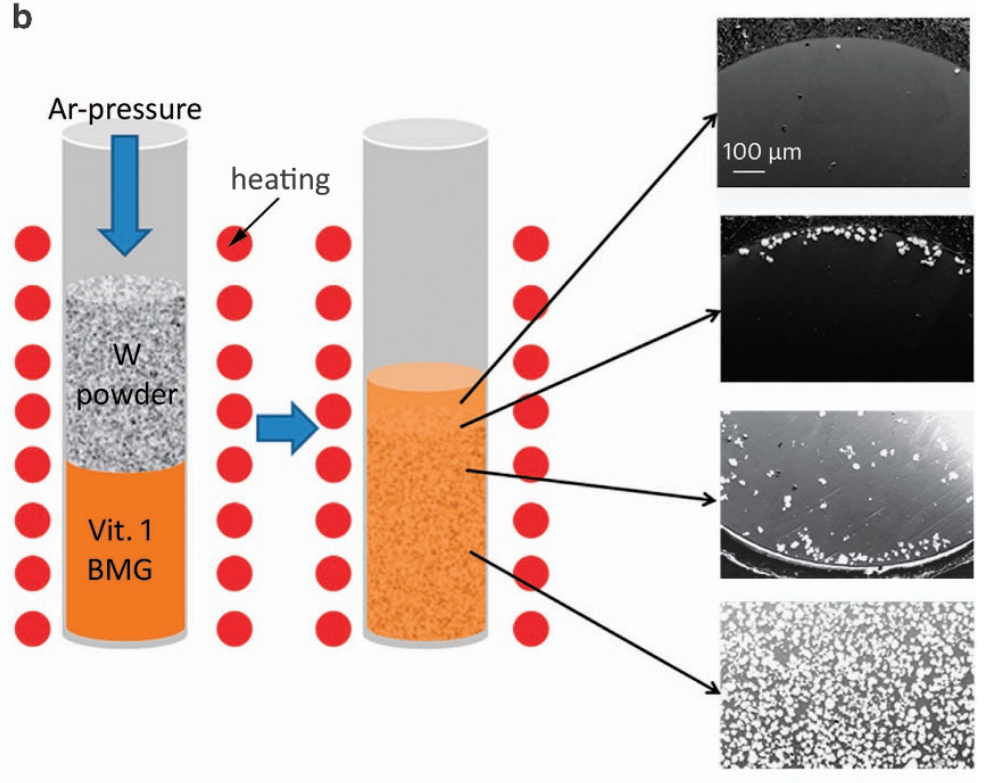

Figure 6. Experiments planned for the ISS using the MSRR. Current NASA and ESA funding is supporting several planned missions on the ISS using the MSRR, shown in a. (b) The current authors, in collaboration with WL Johnson of Caltech, will be performing sedimentation experiments. Composites with vast differences in density between the constitutive phases will be processed in microgravity to avoid sedimentation. The schematic shows the problem with processing these alloys on Earth. The denser phase simply sinks in the melt, preventing a homogeneous distribution. Other experiments are being planned by investigators from a number of countries. BMG, bulk metallic glass; ESA, European Space Agency; ISS, International Space Station; MSRR, Materials Science Research Rack; NASA, National Aeronautics and Space Administration.

astronauts. In 2009, the space shuttle Discovery (STS-128), took the Materials Science Research Rack (MSRR), a new processing facility for metal alloys, to a permanent home on the ISS (see NASA's Research and Technology page: http://www.nasa.gov/mission_ pages/station/research/experiments/327.html). The MSRR, developed jointly by European Space Agency and NASA, is equipped with two interchangeable furnaces, a low-gradient furnace and a solidification and quenching furnace, which allow cylindrical samples over a centimeter in diameter to be processed in microgravity. Currently, space agencies such as NASA, European Space Agency, DLR, Japan Aerospace Exploration Agency, and Canadian Space Agency, as well as scientists worldwide are collaborating on projects. Under the NASA funding, the current authors have been exploring ground-based experiments related to how dendrites grow in BMGMCs. ${ }^{10,43}$ For the upcoming flight experiments, the authors will be investigating BMGMCs with dense inclusions of $\mathrm{W}$ and $\mathrm{Ta}$, intended for heavy alloys such as those used in kinetic energy penetrators. Ground-based testing on these alloys has been hampered by sedimentation of the crystalline phases, which have up to three times higher density than the glass matrix. Figure 6a shows an image of the MSRR that is currently installed on the ISS. The current authors will be exploring sedimentation in BMGMCs using the MSRR based on ground-based experiments, shown in Figure 6b. Tungsten particles were infiltrated with a BMG Vitreloy 1 to form a composite. The composite was inverted and remelted but the tungsten particles sediment normal to the direction of gravity, creating a nonhomogeneous sample, seen in Figure $6 \mathrm{~b}$. On orbit, these samples will be fabricated with microstructures that would be difficult to obtain on Earth, due to the density difference between the BMG matrix and the heavy particles.

Microgravity research in metallic glasses and BMGs has been funded nearly continuously for 30 years and the combination of ground-based and microgravity experiments has pushed the field to the cusp of widespread commercialization. It is anticipated that future uses of BMGs in the space environment will be focused on structural spacecraft components, such as debris shields, paneling, cellular structures, mirrors, compliant mechanisms, and gears.

\section{ACKNOWLEDGMENTS}

This work was supported by NASA's Exploration Systems Mission Directorate under contract no. NNH10ZTT001N. Part of this work was completed at the Jet Propulsion Laboratory, California Institute of Technology, under contract with NASA. We thank WL Johnson, MD Demetriou, and HJ Fecht for supplying reference materials and S Bossuyt for discussions.

\section{COMPETING INTERESTS}

The authors declare no conflict of interest.

\section{REFERENCES}

1 Chiaramonte F, Greenberg P, Johnson WL, Weislogel M. Strange behavior: the odd effects of microgravity help nasa and its partners advance physical science and innovative technologiesIn NASA's Magazine for Business \& Technology vol 15. NASA: Washington, DC, USAWashington, DC, USA, 2011.

2 Drehman AJ, Greer AL, Turnbull D. Bulk formation of a metallic glass: $\mathrm{Pd}_{40} \mathrm{Ni}_{40} \mathrm{P}_{20}$. Appl Phy Lett 1982; 41: 716-717.

3 Kui HW, Greer AL, Turbull D. Formation of a bulk metallic glass by fluxing. Appl Phy Lett 1984; 45: 615-616.

4 Johnson WL. Bulk glass-forming metallic alloys: science and technology. MRS Bull 1999; 24: 42-56.

5 Telford M. The case for bulk metallic glass. Mater Today 2004; 7: 36-43.

6 Hays CC, Kim CP, Johnson WL. Microstructure controlled shear band pattern formation and enhanced plasticity of bulk metallic glasses containing in situ formed ductile phase dendrite dispersions. Phy Rev Lett 2000; 84: 2901-2904.

7 Szuecs F, Kim CP, Johnson WL. Mechanical properties of $\mathrm{Zr}_{56.2} \mathrm{Ti}_{13.8} \mathrm{Nb}_{5.0} \mathrm{Cu}_{6.9^{-}}$ $\mathrm{Ni}_{5.6} \mathrm{Be}_{12.5}$ ductile phase reinforced bulk metallic glass composite. Acta Mater 2001; 49: 1507-1513. 
8 Hofmann DC, Suh JY, Wiest A, Duan G, Lind ML, Demetriou MD et al. Designing metallic glass matrix composites with high toughness and tensile ductility. Nature 2008; 415: 1085-1089.

9 Hofmann DC, Suh JY, Wiest A, Lind ML, Demetriou MD, Johnson WL. Development of tough, low-density titanium-based bulk metallic glass matrix composites with tensile ductility. Proc Natl Acad Sci USA 2008; 105: 20136-20140.

10 Hofmann DC. Bulk metallic glasses and their composites: a brief history of diverging fields. J Mater 2013; 2013: 1-8.

11 Klement W, Willens RH, Duwez P. Non-crystalline structure in solidified goldsilicon alloys. Nature 1960; 187: 869-870.

12 Lee MC, Kendall JM, Johnson WL. Spheres of the metallic glass $\mathrm{Au}_{55} \mathrm{~Pb}_{22.5} \mathrm{Sb}_{22.5}$ and their surface characteristics. Appl Phy Lett 1982; 40: 382-384.

13 Fecht HJ, Johnson WL. A conceptual approach for noncontact calorimetry in space. Rev Sci Instrum 1991; 62: 1299-1303.

14 Wunderlich RK, Lee DS, Johnson WL, Fecht HJ. Noncontact modulation calorimetry of metallic liquids in low Earth orbit. Phys Rev B 1997; 55: 26-29.

15 Fecht HJ, Wunderlich RK, Glade SC, Johnson WL. Thermophysical properties of bulk metallic glasses in the stable undercooled liquid-a microgravity investigation. MRS Proceedings 2001; 644, L4.5.1-L4.5.6.

16 Wunderlich RK, Fecht HJ. Thermophysical properties of bulk metallic glass forming alloys in the stable and undercooled liquid-a microgravity investigation. Mater Trans 2001; 42: 565-578.

17 Lee DS, Hoffmeister W, Bayuzick R, Johnson WL. Noncontact AC calorimetry: specific heat of liquid $\mathrm{Nb}_{40} \mathrm{Ni}_{60}$ and $\mathrm{Ni}_{24} \mathrm{Zr}_{76}$ as measured on IML-2. Thermophysical Joint Conferences. Proceedings Of the 4th Asian Thermophysical Properties 1995, 884-888.

18 Robinson MB. Microgravity Science Laboratory (MSL-1) Final Report. Proceedings of the Microgravity Science Laboratory 1998, Report no. NASA/CP-1998-208868.

19 Egry I, Lohöfer G, Seyhan I, Schneider S, Feuerbacher B. Viscosity of eutectic $\mathrm{Pd}_{78} \mathrm{Cu}_{6} \mathrm{Si}_{16}$ measured by the oscillating drop technique in microgravity. Appl Phy Lett 1998; 73: 462-464.

20 Egry I, Lohöfer G, Seyhan I, Schneider S, Feuerbacher B. Viscosity and surface tension measurements in microgravity. Int J of Thermophysics 1999; 20: 1005-1015.

21 Peker A, Johnson WL. A highly processable metallic glass: $\mathrm{Zr}_{41.2} \mathrm{Ti}_{13.8} \mathrm{Cu}_{12.5^{-}}$ $\mathrm{Ni}_{10.0} \mathrm{Be}_{22.5}$. Appl Phy Lett 1993; 63: 2342-2344.

22 Lin XH. Bulk glass formation and crystallization of Zr-Ti-based alloys. PhD Dissertation, California Institute of Technology, 1997.

23 Lin XH, Johnson WL. Formation of Ti-Zr-Cu-Ni bulk metallic glass. J Appl Phys 1995; 78: 6514-6519.

24 Jurewicz AJG et al. The Genesis solar-wind collector materials. Space Sci Rev 2003; 105: 535-560.

25 Hays CC, Schroers J, Johnson WL, Rathz TJ, Hyers RW, Rogers JR et al. Vitrication and determination of the crystalline time scales of the bulk-metallic-glass-forming liquid $\mathrm{Zr}_{58.5} \mathrm{Nb}_{2.8} \mathrm{Cu}_{15.6} \mathrm{Ni}_{12.8} \mathrm{Al}_{10.3}$. Appl Phy Lett 2001; 79: 1605-1607.

26 Grimberg A, Burnett DS, Bochsler P, Baur H, Wieler R. Composition of light solar wind noble gasses in the bulk metallic glass flown on the Genesis mission. Space Sci Rev 2007; 130: 293-300.

27 Wiens RC, Burnett DS, Hohenberg CM, Meshik A, Heber V, Grimberg A et al. Solar and solar-wind composition results from the Genesis mission. Space Sci Rev 2007 130: 161-171.

28 Burnett DSGenesis Science TeamGS. Solar composition from the Genesis mission. Proc Natl Acad Sci USA 2011; 108: 19130-19134.

29 Grimberg A, Baur H, Bühler F, Bochsler P, Wieler R. Solar wind helium, neon, and argon isotopic and elemental composition: Data from the metallic glass flown on NASA's Genesis mission. Geochim Cosmochim Acta 2008; 72: 626-645.

30 Grimbers A, Baur H, Bochsler P, Bühler F, Burnett DS, Hays CC et al. Solar wind from Genesis: Implications for the lunar noble gas record. Science 2006; 314 1133-1135.

31 Veazey C, Demetriou MD, Schroers J, Hanan JC, Dunning LA, Kaukler WF et al. Foaming of amorphous metals approaches the limit of microgravity forming J Adv Mater 2008; 40: 7-11.
32 Schroers J, Veazey C, Johnson WL. Amorphous metallic foam. Appl Phy Lett 2003 82: $370-373$.

33 Schroers J, Veazey C, Demetriou MD, Johnson WL. Synthesis method for amor phous metallic foam. J of Appl Phy 2004; 96: 7723-7730.

34 Davidson M, Roberts S, Castro G, Dillon RP, Kunz A, Kozachkov H et al. Investigating amorphous metal composite architectures as spacecraft shielding. Adv Eng Mater 2013; 15: 27-33.

35 Hamill L, Roberts S, Davidson M, Johnson WL, Nutt S, Hofmann DC. Hypervelocity impact phenomenon in bulk metallic glasses and composites. Adv Eng Mater 2014; 16: 85-93.

36 Rhim WK, Chung SK, Barber D, Man KF, Gutt G, Rulison A et al. An electrostatic levitator for high temperature containerless materials processing in $1 \mathrm{~g}$. Rev Sci Instrum 1993; 64: 2961-2970.

37 Kim YJ, Busch R, Johnson WL. Metallic glass formation in highly undercooled $\mathrm{Zr}_{41.2} \mathrm{Ti}_{13.8} \mathrm{Cu}_{12.5} \mathrm{Ni}_{10.0} \mathrm{Be}_{22.5}$ during containerless electrostatic levitation processing. Appl Phy Lett 1994; 65: 2136-2138.

38 Ohsaka K, Chung SK, Rhim WK, Peker A, Scruggs D, Johnson WL. Specific volumes of the $\mathrm{Zr}_{41.2} \mathrm{Ti}_{13.8} \mathrm{Cu}_{12.5} \mathrm{Ni}_{10.0} \mathrm{Be}_{22.5}$ alloy in the liquid, glass and crystalline states. Appl Phy Lett 1997; 70: 726-728.

39 Schroers J, Johnson WL. History dependent crystallization of $\mathrm{Zr}_{41} \mathrm{Ti}_{14} \mathrm{Cu}_{12} \mathrm{Ni}_{10} \mathrm{Be}_{23}$ melts. J Appl Phy 2000; 88: 44-48.

40 Schroers J, Johnson WL. Repeated crystallization in undercooled $\mathrm{Zr}_{41} \mathrm{Ti}_{14} \mathrm{Cu}_{12^{-}}$ $\mathrm{Ni}_{10} \mathrm{Be}_{23}$ liquids. Appl Phy Lett 2000; 74: 2343-2345.

41 Busch R, Kim YJ, Schneider S, Johnson WL. Atom probe field ion microscope and levitation studies of the decomposition and crystallization of undercooled Zr-Ti-Cu-Ni-Be melts. Mat Sci Forum 1996; 225-227: 77-82.

42 Schroers J, Johnson WL. Crystallization kinetics of the bulk-glas-forming $\mathrm{Pd}_{43} \mathrm{Ni}_{10} \mathrm{Cu}_{27} \mathrm{P}_{20}$ melt. Appl Phy Lett 2000; 77: 1158-1160.

43 Kozachkov H, Kolodziejska JA, Roberts S, Li JJZ, Johnson WL, Hofmann DC. Study of mushy-zone development in dendritic microstructures with glass-forming eutectic matrices using electrostatic levitation. ISRN Mater Sci 2013; 108363 : $1-7$

44 Inoue A, Takeuchi A. Recent development and application products of bulk glassy alloys. Acta Materialia 2011; 59: 2243-2267.

45 Nishiyama N, Amiya K, Inoue A. Novel applications for bulk metallic glass for industrial products. J Noncryst Sol 2007; 353: 3615-3621.

46 Homer ER, Harris MB, Zirbel SA, Kolodziejska JA, Kozachkov H, Trease BP et al. New methods for developing and manufacturing compliant mechanisms utilizing bulk metallic glass. Adv Eng Mater 2014.

47 Duan G, Wiest A, Lind M-L, Li J, Rhim WK, Johnson WL. Bulk metallic glass with benchmark thermoplastic processability. Adv Mater 2007; 19: 4272-4275.

48 Schroers J. Processing of bulk metallic glass. Adv Mater 2010; 22: 1566-1597.

49 Liu YH, Wang G, Wang RJ, Zhao DQ, Pan MX, Wang WH. Super plastic bulk metallic glasses at room temperature. Science 2007; 315: 1385-1388.

50 Schroers J, Hodges TM, Kumar G, Raman H, Barnes AJ, Pham Q et al. Thermoplastic blow molding of metals. Mater Today 2011; 14: 14-19.

51 Johnson WL, Kaltenboech G, Demetriou MD, Schramm JP, Liu X, Samwer K et al. Beating crystallization in glass-forming metals by millisecond heating and processing. Science 2011; 13: 828-833.

52 Kumar G, Tang HX, Schroers J. Nanomoulding with amorphous metals. Nature 2009; 457: 868-871.

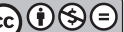

This work is licensed under a Creative Commons AttributionNonCommercial-NoDerivatives 4.0 International License. The images or other third party material in this article are included in the article's Creative Commons license, unless indicated otherwise in the credit line; if the material is not included under the Creative Commons license, users will need to obtain permission from the license holder to reproduce the material. To view a copy of this license, visit http:// creativecommons.org/licenses/by-nc-nd/4.0/ 